\title{
Biometric Worlds of the Body. Quantified-self Activities in Post-media Projects
}

\author{
Ewelina Twardoch-Raś
}

\begin{abstract}
The article proposes to investigate problem of parametrization of the human body in the selected artistic projects, combining art and science, that are based on biotechnological experiments and biometrics. All of the projects use specific quasimedical tools and devices (so called self-trackers) and procedures of measurement, diagnosis, therapy, etc. to monitor and improves the organism. The projects are created in reference to the Quantified-Self movement, relative new trend (2008), based on the regular measurement of one's vital functions for diagnostic, self-cognitive and enhancement purposes. In my paper I would like to consider the roots of this movement (beginning with the activities of Sanctorius of Padua from XVI century) and present the transmedia projects of American artist: Laurie Frick and Stephen Cartwright ("Walking", "Sleep patterns", "Chromatic data oscillator"). I investigate the projects as the new forms of auto-ethnography that are based on regular measurement of vital functions of one's organism to better understand, control and optimize body's condition and efficiency.
\end{abstract}

Keywords-Biometrics, Body, Quantified-Self, Autoethnography, Parametrization

\section{INTRODUCTION}

In my article I would like to introduce a problem of enhancement and development of the human body in some artistic projects, combining art and science, that are based on specific biometric systems. This topic is a part of my broader research on the roles and functions of bio-data in so called new media art in the perspective of posthumanistic and transhumanistic philosophy. Before I will present selected projects in which the problem of enhancement and development of the human organism was taken, I would like to explain a few categories and phenomena that form the basis for my considerations.

First of all, I consider the referenced projects in the broader context of post-media art. As defined by Melvin L. Alexenberg, the category of postmedia art implies artistic projects that are created as a result of the interaction between the digital, biological, cultural, and social, between virtuality and reality, embodied media and augmented space, between sensual experiences, community narratives, and network practices [1]. Although these projects are generally based on matter rightly called wetware by Roy Ascott [2], that is on an

Ewelina Twardoch-Raś, Jagiellonian University in Cracow, Poland. organic, carnal medium, this medium also co-exists with digital registration. All of the projects would have been impossible to create without the use of appropriate computer software and technics of creative visualization.

Second of all, such projects are also a part of a broad field of so called art\&sience, created in a conscious manner since the 1940s. Art\&science works combine artistic expression with often the latest scientific discoveries and achievements in the field of technics, engineering and biotechnology. These are often projects that do not focus on aesthetic ideas, but are a conceptual art that critically reflects on important social and cultural problems. [3] The projects I am analyzing I call a biometrics art, which is basically a combination of biological and generative art.

\section{BIOMETRICS AND STRATEGIES OF PARAMETRIZATION}

Biometrics means systems and strategies of body measurements and calculations with using specific devices (as scanner for instance) to get some kind of human characteristics, which are often categorized as physiological versus behavioral characteristics. Examples of the first type include, but not limited to fingerprint, palm veins, face recognition, DNA, palm print, hand geometry, iris recognition, retina and scent, as well as heart rate or the skin-galvanic reactions of our body. Behavioral characteristics are the type of our gait or rhythm and timbre of voice. So, in short biometric systems bring ways of describing living beings by using procedures of parameterization of bodily functions. [4]. All of the projects I analyzed use specific quasi-medical tools (usually self-constructed devices and software) and methods (methods of diagnosis, therapy and of sensory-motor body functions' improvement) to create such kind of organism characteristics and to show some possibilities in a way of body extension and development. Of course, it is possible to analyze biometric projects in many contexts of philosophy and activism in the field of transumanism, but I would like to refer them in a more or lesser order to the specific movement associated with transhumanist ideas, which is called Quantified-Self.

\section{QUANTIFIED-SELF}

Quantified-Self is on the one hand decentralized movement or community of users which have been proposed in San Francisco, CA, by Wired Magazine editors Gary Wolf and 
Kevin Kelly in 2007 and in 2010, Wolf spoke about the movement at TED. Now, in a broader sense of everyday activities it is rather relative new trend, based on the regular measurement of one's vital functions for diagnostic, selfcognitive and enhancement purposes. As claims Melanie Swan "The quantified self (QS) is any individual engaged in the selftracking of any kind of biological, physical, behavioral, or environmental information. There is a proactive stance toward obtaining information and acting on it. A variety of areas may be tracked and analyzed, for example, weight, energy level, mood, time usage, sleep quality, health, cognitive performance, athletics, and learning strategies" [5]. It is generally the strategy of using wearable sensors in combination with wearable computing and wireless communication.

Today we generally use so called wearable technology, so the trackers (based on accelerators, gyroscopes motion sensor, and mobile sensor of EEG and EKG) of that we literally can wear, as smartwatch, bracelets, wearable cameras, smart clothing, smart glasses and applications in our smartphones. Some of them allow the so-called biofeedback, so the process of gaining greater awareness of many physiological functions primarily using instruments that provide information on the activity of those same systems, with a goal of being able to manipulate them at will. It means that within self-tracking methods we can manage the affective reactions of our body, as heart rate or muscles tensions [6].

Such an individual variant of bio-tracking is called selftracking activities. As transhuamanist idea quantified self is therefore self-knowledge through self-tracking with technology; it is a self-optimization through continuous selfmonitoring to improve life functions, the development of the body, and self-awareness. It is therefore also body-hacking in opposition to bio-hacking. While bio-hacking involves internal interferences into the body (using chips and implants), bodyhacking means hacking body knowledge through connected with the organism, but rather external systems and using this information to optimize and extend the body's function - so not by prosthetics, but by physical and mental exercises, good sleep and nutrition, and sometimes by pharmacology as well.

Moreover, as claims Gina Neff and Dawn Nafus, personal practices of self-tracking also turn also into collective phenomena that organize the dynamics of social change, and around them and in relation to them, a huge industry is developing, not only technological. The data obtained in this way is used by various institutions from state to private companies, which is why self-tracking seems to be an ideal scenario for the development of modern biopolitical mechanisms, which, starting from the needs of individuals, focus on population management. What is more, the social coercion of physical and mental efficiency also takes on more specific manifestations, such as 'Community tracking' also known as civic science, initiatives consisting in offering their data defining biological functions for specific social purposes, e.g. Open Path, Open fMRI, and so called 'forced tracking' ("pushed tracking") and imposed tracking which consist in ordering employees by employers to carry out selfparameterization processes [7]. Such bio-data processing in multimodal systems can be seen as affective version of dataveillance. It also should not be forgotten that this is a technological idea with a huge marketing and economic potential - and as numerous reports show (including ABI ones) Wearable Computing Devices is one of the most dynamically developing markets in the field of computing [8].

\section{HISTORICAL ROOTS OF QUANTIFIED-SELF}

It is worth to mention that some of the researchers claim that the beginning of using personal wearable devices is visible since the late 19th century, when the weight scale has become one of the most pervasive and familiar self-monitoring technologies. 'In 1885, the public 'penny scale' was first invented in Germany, and shortly after began appearing in the United States in groceries and drug stores [9]. It was modeled after the grandfather clock, with a large dial, and once customer stepped on the weighing plate and placed a penny in the slot, the spring would move the arrow to indicate the number of pounds'.

But, according to Swan again, "One of the earliest recorded examples of quantified self-tracking is that of Sanctorius of Padua, [also called Santorio Sanctorius], who studied energy expenditure in living systems by tracking his weight versus food intake and elimination for 30 years in the 16th century" [5]. He is particularly famous for a measurement device he constructed called the "weighing chair," which he used to track his and his patients' weight. The oldest, known relic of a weighing scale dates back to around $2000 \mathrm{BC}$ in the Indus Valley near present day Pakistan. But Sanctorio's weighing chair used the same measurement principles as the classic counter-weight scale. Probably in 1612 the inventor also published a work entitled "Sanctorii Commentaria in Artem medicinalem Galeni," in which he introduces the thermoscope and various aspects of quantification in medicine. This work is considered to be the first Western treatise on quantification in medicine. Sanctorius is also inventor of pulsilogium, so a device to measure one's pulse rate [10].

It is very interesting root of quantified-self connected with lifelogging idea, but in my opinion, we should rather recognize the beginning of the very idea of bio-tracking together with around the 1960s, when sensors reading vital functions by registering biosignals from the body began to be more and more advanced and precise. Nowadays we generally use so called wearable technology, so the trackers (based on accelerators, gyroscopes motion sensor, and mobile sensor of EEG and EKG) of that we literally can wear, as smartwatch, bracelets, wearable cameras, smart clothing, smart glasses and applications in our smartphones. The first device's prototype of the whole body's monitoring was created in 1996 by Steve Mann. Quantimetric self-sensing apparatus consists of sensing 
heart (ECG), brain (ECG), video, respiration, skin conductivity, and numerous other quantities, which was streaming live to the Internet, on the World Wide Web.

\section{LAURIE FRICK'S ARTISTIC PROJECTS}

In the last part of the paper I would like to show how the ideas of self-tracking and technological management of affective reactions are tracked in art and science practices. I call them the new forms of auto-ethnography that are based on regular measurement of vital functions of one's organism to better understand, control and optimize body's condition and efficiency. Such kind of transhumanist auto-ethnography's practices develop American artists Laurie Frick and Stephen Cartwright in their transmedia projects ("Walking", "Sleep patterns", "Chromatic data oscillator"). Such projects negotiate the meaning of traditional literary auto-narrations (as journals or diaries) and show new context of creating narrative identities - based on transhumanistic connections with wearable, smart technologies.

At first I will focus on the works created by Laurie Frick. She created data installations and just the visual representation of body-data by using creative design methods. Laurie Frick is involved in the Quantified-Self movement, using various biotracking capabilities that provide mobile devices, and created portraits - installation cycles based on data obtained from body parameterization processes. She gave the symptomatic motto to her artistic practices, which is: 'anticipating the future of data about you' [11]. It means, that the full knowledge about ourselves is just a matter of the near future. The mystery of human beings - in her opinion - which is in fact very utopian vision, is encoded in algorithmised data that will tell us everything about us, destroying the essentialistic illusion of our secret and unavailable identity.

According to the artist, human identity is just somatic ones, what means that it is measurable and what is more expandable, especially by an alliance with technologies, to use the words of Rosi Braidotti [12]. Art installation and data tells the new kind of story of ourselves - it is the story of our affective reaction, that we can investigate as a form of very personal journal, which is also based on objective patterns.

Frick cycles revolve around activities that are most often subject to bio-tracking, such as "Walking" and "Sleep Drawing", "Sleep Patterns". The artist also included, however, parameterization of stress levels ("Stress Inventory", "Mood + Quantify") and serious illnesses - such as amyotrophic lateral sclerosis ("7 Stages of ALS").

In her very simple project "Waking" from 2012-2015 she used her application "Frickbits" on Iphone (so motion sensors, cameras and GPS) to collect data of daily movement and cumulatively display her walking patterns. Then she created these hand-build, laser-printing collage works based on software algorithm to show such patters, to tell the story of her own movement from the three years of her life. It is a kind of personal cartography [11].
Much more interesting is however her installations 'Walking, Eating, Sleeping'. The goal of the installation is to create a kind of immersive space of data, to sense repetition and frequency of the body reactions. Instead of expressing events of the body just in numbers, Frick experiments with patterns that mark the condition of our daily selves, something she calls "human data portraits." Using 3D printing and laser cutters, intricate designs are carved in wood and suspended from the ceiling. Frick's art is layered and stacked, featuring patterns encased in rectangular compositions. They vary by piece and abstractly depict how groups of people experience things in a day. Walking, for instance, looks like a map of a city, with gridded roads and clusters of buildings. The work is hung at different levels and directions, referencing multiple lives and timelines. They are a visual record of how we feel, our stress level, and mood. The result of Frick's findings produce beautiful cutouts that are enjoyed both intellectually as well as aesthetically [11].

Even if these projects are probably a form of representation that can play a therapeutic role rather than a therapy in itself, methods and applications can bring specific diagnostic and therapeutic effects and therefore are defined as assistive technologies. According to a 2012 Pew Research Center survey, $69 \%$ of U.S. adults use tracking to manage their health or that of a loved one. What is more, the research of Mayara Figueiredo's group (2018) shows that "routine self-tracking, as opposed to occasional, event-triggered tracking, is more likely to result in positive changes to health management approaches" [13]. These data show that bio-tracking not only enables more conscious management of body functions, but also generates daily healthy habits that are very important in monitoring chronic diseases.

As Sara Riggare said in her blog-journal: "Self-tracking is, in my opinion, the most powerful weapon I can wish for in my battle against Parkinson's disease (PD). (...) Why? I see my neurologist twice a year, about half an hour every time. That's one hour per year in healthcare for my Parkinson's disease. During the same year I spend 8,765 hours in selfcare, applying my knowledge and experience together with what I get from my neurologist to manage a difficult condition as best I can" [14]. What she also emphasizes is the sense of independence (from institutional regime) and experience of solidarity with other diseased people.

According to Dorthe Brogård Kristensen and Minna Ruckenstein in cases of people suffer from chronic bodily or mental diseases and disabilities who uses self-tracking technologies we can talk about very specific, unprecedented and real, new forms of co-evolving humans with technology and humans enhancement. Patients often literally grow into the used tools (not without reason they are called wearable), creating a special form of cyborg's symbiosis [15].

Such methods as therapeutic solution we can see e.g. in the George Khut's project „BrightHearts” (based on biofeedback method, that help diseased children to deal with medical procedures) and in Rosalind W. Pickard's wearable 
technologies' projects "Affectiva" and "Emotica" that help people with depression and mental disorders with monitoring changes in moods and emotions, so both projects are an attempt to better understanding of mental wellness.

Other Frick projects are based solely on data collected by sensors in trackers and mobile devices and are developed by computer programs, but ultimately they do not take the form of numerical or digital visualization, but rather printouts from a $3 \mathrm{D}$ printer or created with the help of a laser. The artist places them on the walls in galleries (as a set of squares, rectangles or other figures made of paper and metal), hangs in the form of laser cut "screens" of paper, plywood or various metal alloys in the entire empty gallery room, yes, that we have the impression of moving between our own biological data. She also arranges them into various figures made of small wooden elements [11].

These statements reflect patterns illustrating our affective activities recorded during the day, week, month. Elements of the installation are often numbered, have different colors, sometimes they are also so included in the arrangement of the gallery room that it is difficult to distinguish them from the decorative elements of the interior. Such methods of exposure correspond to the assumptions of Frick that everything that is related to our being in the world can be expressed with the help of data, and thus also control, improve, change.

\section{STEPHEN CARTWRIGHT'S ARTISTIC PROJECTS}

Stefan Cartwright is an artist who uses both traditional selfobservation methods and those enabled by self-tracking devices. Cartwright's basic assumption is to monitor the movement of the Earth's surface using a portable GPS (usually the one built into a smartphone). The registration applies to many hours of walking, carried out by the creator every day. Data obtained in this way are automatically saved in the form of spreadsheets, from which 3D maps are generated, visualizing the artist's location in space [16].

The main project, implemented using this method since 1996, has been continuously titled "Latitude and Longitute Project". It is presented in the form of 3D visualizations, based on cartographic diagrams, in which visual codes represent the artist's bodily presence in real space [17].

A similar assumption - illustrating the "nesting" of the biological being in the reality determined by atmospheric processes - Cartwright implements in the project "Chromatic data oscillator". By measuring atmospheric values (air temperature, length of the day, wind speed) and daily activities such as: the length of cycling during the day, the moment when the artist wakes up every day, the time spent walking and meditating, Cartwright created a "programmable sculpture", made of aluminum, an electronic system and LED bulbs, which when connected to the power mapping the relationship between the information obtained. Algorithmic data sets make light bulbs glow in different colors and light waves vibrate at different frequencies [18].
In "Range," Cartwright designed a sculpture of eight movable panels, which changes its shape in relation to the average mileage that the artist traveled in 2002-2009 [19]. In yet another implementation of "Deviation", which also has the form of Cartwright's "programmable sculpture" with the help of light panels, emitting light in two colors, connected to a complex electrical system, sets two types of data: sunrise time and the time the artist woke day. Parameterization, carried out using the application, lasted for a year and was intended to enter the onset of the biological activity of the body followed with waking from sleep with the symbolic beginning of a new day, the awakening of nature [20].

Cartwright's projects, with the help of parameterization tools, inscribe the daily rhythm of an individual's life into the order of nature, while both the functions of the biological body and nature take the form of measurable data in the project. Nature is the object of reflection and political action, as well as what biological conditions social and political activity. Thus, everyday activities parameterized in the context of the circadian rhythm conditioned by nature become, in the artist's projects, units of vitality. This vitality consists of the number of miles traveled (by bike and on foot), the natural waking time, the number of meditations that were supposed to provide Cartwright with internal peace and connect it with nature more strongly. The creator did not limit himself to obtaining biological data only, but did so by referring them directly to the specific perspective defining them. The laws of nature were here each time determined in a cultural and semiotic way - through diagrams, charts, measurements relating to the basic units of reality: time and space. So it was a nature whose vitality was also parameterized and inscribed in socio-political processes.

This orientation of the artist is emphasized by the titles of projects in which words such as: scope, deviation, data oscillator, longitude and latitude have been included. Cartwright in his projects argues that the "naturalization" of life, which Foucault wrote about, as a biopolitical action, at the individual level can also manifest itself through a couple life functions in relation to measurable vitality of nature.

In the times of late capitalism, it is no longer about the single-line exploitation of nature, but about such inclusion in political activities that will make these spheres inseparable areas of activity. It is similar with a biological body, whose economic value does not result from domination based on the destruction of the body, but on its improvement. Increasing productivity in both cases means not protecting what is natural, but increasing profits. The monitoring processes analyzed by Cartwright in his projects perfectly point to this parallelism of recording and managing body space and environment data, whose exploration shaped the contemporary technoculture paradigm, and also influenced the development of biopolitical processes. 


\section{CONCLUSION}

Artists are constantly looking for new ways of creative expression. One of them is the use of biotracking tools and methods to create bodily diaries that are used for selfobservation, which has a wide diagnostic potential. These measurements are sometimes imprecise and are based on algorithmic reductionism, therefore they cannot be the source of the truth about the human being. On the other hand, however, they also express the modern sense of uncertainty of individuals and show man's faith in the machine definition of personality traits. Bio-tracking practices are also certainly one of the newest methods of self-knowledge related to the development of new personal technologies.

In my article I showed two variants of artistic expression related to bio-tracking and the Quantified-Self movement, but there are many more artists using biotracking tools. In their works they show that biometric procedures are not only used for surveillance and creating security systems based on identification, but can be a tool for artistic creation - a new form of storytelling and narrative strategies.

\section{REFERENCES}

[1] L. Alexenberg, The Future of Art in a Postdigital Age. From Hellenistic to Hebraic Consciousness. Bristol: Intellect Books, 2011, pp. 33-96.

[2] R. Ascott, Reframing Consciousness. Art, mind and technology. ExeterPortland: Intellect Ltd., 2001, p. 188.

[3] S. Wilson, Information Arts. Intersections of Art, Science, and Technology. Cambridge-London: The MIT Press, 2002, pp.26-30.

[4] M. Faundez-Zanuy, "Biometric security technology", IEEE Aerospace and Electronic Systems Magazine, no. 21(6), pp. 15 - 26, July 2006. https://doi.org/10.1109/MAES.2006.1662038

[5] M. Swan, "The Quantified-Self: Fundamental Disruption in Big Data Science and Biological Discovery", Big Data, no. 2, p. 85, 2013. https://doi.org/10.1089/big.2012.0002 .

[6] K. W. Brown, R. M. Ryan, "The Benefits of Being Present: Mindfulness and Its Role in Psychological Well-Being”, Journal of Personality and Social Psychology, no. 4, vol. 84, pp. 822-848, 2003. https://doi.org/10.1037/0022-3514.84.4.822

[7] G. Naff, D. Nafus, Self-tracking. Cambridge-London: The MIT Press, 2016, pp. 25-26. https://doi.org/10.7551/mitpress/10421.001.0001

[8] Wearable Computing Devices, Like Apple's iWatch, Will Exceed 485 Million Annual Shipments by 2018, available at: https://www.abiresearch.com/press/wearable-computingdevices-like-apples-iwatch-will/, [access: 20.09.2019].

[9] H. Schwartz H, Never Satisfied: A Cultural History of Diets, Fantasies and Fat. New York: The Free Press, p. 186.

[10] K. Crawford, "Our metrics, ourselves: A hundred years of selftracking from the weight scale to the wrist wearable device", European Journal of Cultural Studies, Vol. 18(4-5), pp. 481-482, 2015 https://doi.org/10.1177/1367549415584857

[11] Webpage of the artist: https://www.lauriefrick.com/, [access: 21.09.2019].

[12] R. Braidotti, Posthuman. Cambridge: Polity Press, 2013, p. 103, 111.

[13] M. Figueiredo, C. Caldeira, K. Zheng, "Routine self-tracking of health: reasons, facilitating factors, and the potential impact on health management practices", AMIA Annual Symposium Procceding, 2017, pp. 706-714, available at: https://www.ncbi.nlm.nih.gov/pmc/articles/PMC5977566/, [access: 25.09.2019].

[14] https://www.riggare.se/saras-self-tracking/, [access: 25.09.2019].

[15] D. Brogård Kristensen, M. Ruckenstein, "Co-evolving with self-tracking technologies”, New Media \& Society, Vol 20, Issue 10, 2018, available at: https://journals.sagepub.com/doi/abs/10.1177/1461444818755650, [access: 26.09.2019].

[16] The Webpage of artist: http://www.stephencartwright.com/about, [access: 26.09.2019].

[17] The Webpage of the project: http://www.stephencartwright.com/\#/latitude-andlongitude-project/ [access: 26.09.2019].

[18] The Webpage of the project http://www.stephencartwright.com/\#/chromatic-dataoscillator-test/ [access: 26.09.2019],

[19] The Webpage of the project: http://www.stephencartwright.com/\#/range/ [access: 27.09.2019].

[20] The Webpage of the project: http://www.stephencartwright.com/\#/deviation/ [access: 27.09.2019]. 